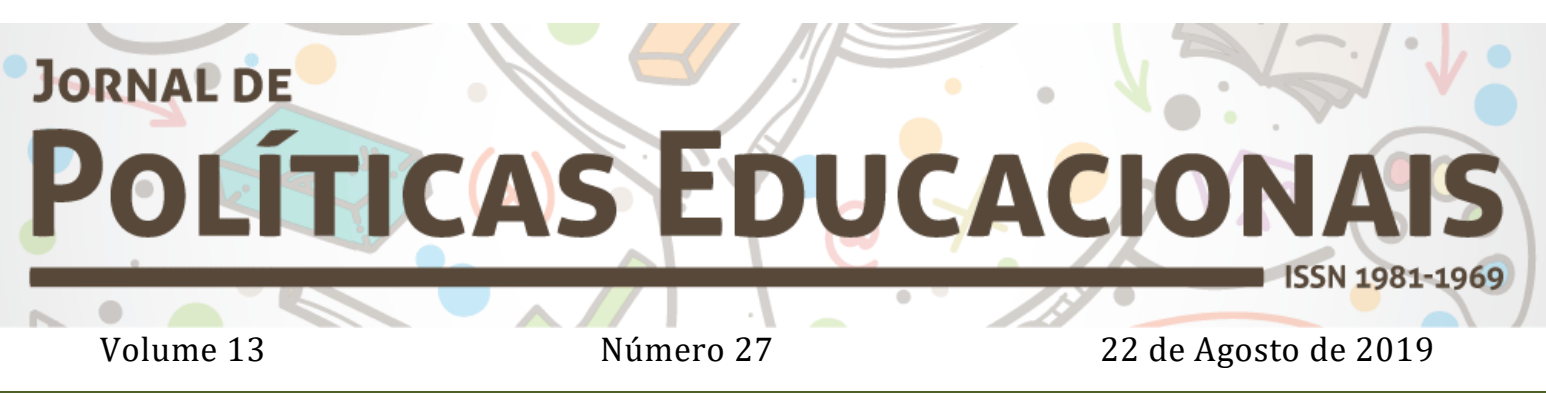

\title{
O Programa de Metas Municipais: promessas de uma nova gestão
}

\section{The Municipal Goals Program: promises of a new management}

\section{El Programa de Metas Municipales: promesas de una nueva gestión}

\author{
Regina Maria Duarte Scherer ${ }^{1}$
}

Citação: SCHERER, Regina Maria Duarte. O Programa de Metas Municipais: promessas de uma nova gestão. Jornal de Políticas Educacionais. V. 13, n. 27. Agosto de 2019.

\section{Resumo:}

0 presente artigo procura analisar o Programa de Metas (Prometa), uma política em implantação no município de Porto Alegre, exigido por determinação de emenda à Lei Orgânica Municipal, no ano de 2015, e elaborado pela primeira vez pela gestão municipal iniciada em 2017. O objetivo principal foi analisar as conexões entre o texto produzido e o contexto da prática, sem deixar de localizar os atores que influenciaram sua elaboração. 0 estudo propiciou pesquisar o texto que deu origem à alteração na lei, localizar as conexões com o Programa Cidades Sustentáveis e analisar como o texto produzido foi posto em prática pela atual gestão municipal, como conteúdo do Prometa encaminhado para a Câmara de Vereadores, em atendimento à legislação. Para realizar as reflexões ao longo do artigo, foram escolhidos autores como Mainardes (2006), Draibe (2001) e Arretche (2001).

Palavras-chaves: Gestão municipal. Elaboração de políticas. Políticas educacionais em Porto Alegre.

\begin{abstract}
:
The objective of this article is to analyze the Program of Goals (Prometa), a policy to be implemented in the city of Porto Alegre, required by the amendment to the Municipal Organic Law in 2015 and first elaborated by the municipal management begun in 2017. The objective was to analyze the connections between the produced text and the context of the practice, without forgetting to locate the actors that influenced the elaboration of the same. The study allowed us to research the text that gave rise to the change in the law, find connections to the Sustainable Cities Program and analyze how the text produced was put in place by
\end{abstract}

\footnotetext{
1 Doutora em Educação pelo Programa de Pós-Graduação em Educação da Faced/UFRGS, na linha de Políticas e Gestão de Processos Educacionais. Professora aposentada da Prefeitura Municipal de Porto Alegre/RS. Orcid: https://orcid.org/0000-0003-1220-0811 E-mail: reginascherer@yahoo.com.br
} 
the current municipal administration, as content of the Prometa sent for the City Council in compliance with legislation. To carry out the reflections throughout the article, authors such as Mainardes (2006), Draibe (2001) and Arretche (2001)

Keywords: Municipal Management. Policy Development. Educational Policies in Porto Alegre.

\section{Resumen:}

El presente artículo analiza el Programa de Objetivos (Prometa), una política de implantación en la ciudad de Porto Alegre, requerida por la determinación de la enmienda a la Ley Orgánica Municipal en el año de 2015 y elaborada por primera vez por la administración municipal iniciada en 2017. Fue analizar las conexiones entre el texto producido y el contexto de la práctica, sin olvidar ubicar a los actores que influyeron en la elaboración del mismo. El esfuerzo llevó al estudio del texto que dio lugar al cambio en la ley, a ubicar las conexiones con el Programa de Ciudades Sostenibles y a analizar cómo el texto producido fue puesto en práctica por la administración municipal actual, ya que el contenido de Prometa se envió al Ayuntamiento en legislación. Para llevar a cabo las reflexiones a lo largo del artículo, autores fueron seleccionados, como Mainardes (2006), Draibe (2001) e Arretche (2001).

Palabras clave: Gestión municipal. Desarrollo de políticas. Políticas educativas en Porto Alegre

\section{INTRODUÇÃO}

Uma alteração na Lei Orgânica Municipal - LOM -, ocorrida no segundo semestre de 2015, ganhou visibilidade apenas no início de 2017. Com tal alteração, passou a ser exigida do prefeito a apresentação de um Programa de Metas - Prometa - para os quatro anos do mandato.

É possível que isso seja decorrente da novidade, visto que a atual gestão que assumiu o governo do município de Porto Alegre foi a primeira a ter que apresentar esse programa em atendimento à legislação municipal. Mas também pode ser que a maneira intempestiva como foram encaminhadas as iniciativas de alterações na condução da educação municipal possa ter causado esse efeito, principalmente pelos argumentos usados tanto pelo prefeito como pelo secretário de educação no debate acalorado e cercado de polêmicas levados a público como os servidores municipais.

0 presente artigo tem como proposta analisar os efeitos que a alteração introduzida na Lei Orgânica do município de Porto Alegre possibilitou em termos de elaboração de políticas para a educação municipal. A relevância do tema tem relação com o caráter de novidade que o Prometa assumiu e, também, com o discurso adotado pelo atual prefeito quanto ao caráter inovador que o programa estaria trazendo para a gestão da cidade.

Para isso, a primeira seção do artigo aborda tanto as notícias a respeito da referida legislação, como a análise de seu conteúdo e suas aproximações com programas semelhantes que inspiraram a produção da legislação, apresentando, portanto, alguns elementos do contexto de influência e de produção do texto. Na sequência é apresentado 
o conteúdo do Programa encaminhado para a Câmara de Vereadores pelo gestor atual em atendimento à legislação, ou seja, o que envolve o contexto da prática.

Para realizar as reflexões, ao longo do artigo foram escolhidos autores como Mainardes (2006), Draibe (2001) e Arretche (2001), que também contribuem na apresentação das considerações finais.

\section{O PROGRAMA DE METAS: a lei e sua inspiração}

Com frequência as agendas da gestão pública são tensionadas para incorporarem práticas de planejamento que visem traduzir em metas e estratégias a forma como os recursos do orçamento público serão utilizados. Muitas dessas iniciativas são oriundas de organizações sociais que buscam dar transparência para a forma como são geridos os recursos e que as ações estejam assentadas em políticas que contem com a participação da sociedade na definição das prioridades. Em decorrência disso, o legislativo de algumas cidades vem atuando no sentido de produzir alterações na legislação para criar mecanismos de planejamento e gestão para as políticas locais que possam ser traduzidos em metas, estratégias e indicadores, como é o caso de Porto Alegre, que há pouco tempo passou a contar com legislação que incorpora um programa específico nesse sentido.

A Câmara Municipal de Vereadores de Porto Alegre aprovou em 12 de agosto de 2015 emenda à Lei Orgânica Municipal, na Seção V, no artigo 94, que trata das competências exclusivas do prefeito municipal. 0 texto passou a incluir o inciso XXII e seis parágrafos com a seguinte redação:

XXII - apresentar, em até 90 (noventa) dias após a data de sua posse, o Programa de Metas (Prometa), que compreenderá os 4 (quatro) anos de sua gestão, devendo conter as prioridades, os indicadores de desempenho e as metas quantitativas e qualitativas para cada um dos eixos estratégicos de políticas públicas estabelecidos para a Administração Municipal.

$\S 1$ ㅇ 0 Prometa deverá observar as diretrizes apresentadas na campanha eleitoral, os programas e as ações de governo em andamento, as leis orçamentárias e as deliberações oriundas das assembleias do Orçamento Participativo.

$\S 2^{\circ} \mathrm{O}$ Prometa deverá ser amplamente divulgado em meios de comunicação de fácil acesso à população, tais como mídias digital, impressa, radiofônica e televisiva, e ser publicado no Diário Oficial Eletrônico de Porto Alegre (DOPA-e), devendo tal publicação ser afixada nas sedes da Prefeitura Municipal de Porto Alegre e da Câmara Municipal de Porto Alegre, no dia seguinte ao término do prazo previsto no inc. XXII do caput deste artigo.

$\S 3$ 3o 0 Executivo Municipal promoverá, em até 30 (trinta) dias após o término do prazo referido no inc. XXII do caput deste artigo, audiência pública para apresentação do Prometa. 
$\S$ 4ํNa elaboração e na fixação dos indicadores de desempenho do Prometa, considerar-se-ão as prioridades e as metas estabelecidas para cada um dos eixos estratégicos de políticas públicas da Administração Municipal.

$\S 5$ o 0 Executivo Municipal divulgará, pelo menos 1 (uma) vez ao ano, os indicadores de desempenho qualitativos e quantitativos relativos à execução do Prometa, utilizando meios de comunicação previstos no $\S 2^{\circ}$ deste artigo, assegurando a realização de audiência pública na sede da Câmara Municipal de Porto Alegre, preferencialmente no mesmo momento da apresentação do relatório previsto no inc. VI do caput deste artigo.

$\S$ 6o 0 prefeito poderá, em casos excepcionais, proceder a alterações programáticas no Prometa, justificando-as por escrito e com ampla divulgação pelos meios de comunicação referidos no $\S 2^{\circ}$ deste artigo (PORTO ALEGRE, 2015).

Nesse mesmo ato outra alteração ${ }^{2}$ foi incluída, determinando que as leis orçamentárias do município incorporem "[...] as prioridades, os indicadores de desempenho e as metas quantitativas e qualitativas estabelecidos no Prometa." (PORTO ALEGRE, 2015).

No caso específico de Porto Alegre, a pesquisa a respeito do referido programa iniciou com a busca por notícias na página eletrônica da Câmara de Vereadores e na imprensa e posteriormente ao projeto que deu origem ao Prometa.

A primeira informação foi a notícia localizada na página eletrônica da Câmara de Vereadores a respeito da solenidade pública para promulgar a alteração da lei orgânica, do dia 22 de outubro de $2015^{3}$. Ali consta a informação da promulgação da emenda e traz alguns detalhes quanto à autoria dessa proposição. Tal iniciativa de apresentação da proposta ocorreu no período legislativo de 2009-2012, pelo então vereador Sebastião Melo, e não foi levada à votação naquela legislatura, tendo sido arquivada. A vereadora Jussara Cony, no período legislativo de 2013-2016, solicitou o desarquivamento da proposta e reapresentou o projeto. Na mesma notícia é feito destaque para os nomes das autoridades e convidados presentes no ato de promulgação da emenda, entre os quais destaca-se a presença do coordenador executivo do Programa Cidades Sustentáveis ${ }^{4}$ (PCS). Essa informação chamou a atenção, pois a notícia publicada não oferece outros

\footnotetext{
${ }^{2}$ A alteração está definida no artigo 2º, o qual estabelece a inclusão do parágrafo 6o no artigo 116 da Lei Orgânica.

${ }^{3}$ Disponível em: <http://www2.camarapoa.rs.gov.br/default.php?reg=25493\&p_secao=56\&di=2015-1022>. Acesso em: 13 jan. 2018.

${ }^{4}$ Conforme publicações disponíveis, consta a informação de que o programa existe desde 2010. Em relação aos realizadores desse programa, constam as seguintes informações na página eletrônica: "O Programa Cidades Sustentáveis é uma realização conjunta da Rede Nossa São Paulo, da Rede Social Brasileira por Cidades Justas e Sustentáveis e do Instituto Ethos." Disponível em: <http://www.cidadessustentaveis.org.br/institucional/realizadores>. Acesso em: 13 jan. 2018.
} 
detalhes que permitam ao leitor compreender a ligação existente entre o PCS e a emenda à Lei Orgânica.

Outra publicação relacionada à aprovação do Programa de Metas para Porto Alegre foi localizada no jornal Zero Hora. Trata-se do artigo ${ }^{5}$ publicado em 7 de fevereiro de 2017, cujo autor é o coordenador geral do Programa Cidades Sustentáveis. Ali ele anuncia a chegada do programa a Porto Alegre e enfatiza que tal programa constitui-se em ferramenta importante para o fortalecimento do controle social e de combate à desigualdade. Além disso, Grajew destaca ser fundamental para o processo participativo que o acompanhamento e monitoramento da ações seja efetivado pela sociedade como um todo, além dos integrantes da gestão municipal.

Essas duas notícias motivaram a busca por outras informações em duas frentes: uma a respeito do PCS e a outra quanto à exposição de motivos para o projeto encaminhado na Câmara.

Quanto ao Programa Cidades Sustentáveis, foi possível localizar, no histórico disponível na página eletrônica, que esse programa surgiu em decorrência da experiência iniciada em 2008 na cidade de São Paulo. No material de divulgação do PCS (2012) está registrado que o objetivo dessa inciativa é voltado para o processo de sensibilização e mobilização com vistas ao desenvolvimento sustentável, tanto em seus aspectos econômico e social, como ambiental. Para que tal propósito seja alcançado é enfatizada a necessidade de mobilização e participação tanto da população, como de empresas, organizações sociais e gestores públicos.

No relatório das ações do programa para o período de 2015-2016 (p. 6) está registrado o desafio em torno da mobilização pela aprovação de Proposta de Emenda à Constituição (PEC) que torne obrigatória a "elaboração do plano de metas pelo Poder Executivo municipal, estadual, distrital e federal, com base nas propostas das campanhas eleitorais".

Quanto aos documentos arquivados na Câmara de Vereadores, na exposição de motivos que acompanha a proposta de emenda à lei orgânica ${ }^{6}$ está afirmada a

\footnotetext{
${ }^{5}$ De autoria de Oded Grajew, diretor do Instituto Ethos e um dos criadores do Fórum Social Mundial, o artigo tem como título: Lei do Plano de Metas chega a Porto Alegre. Disponível em: $<$ https://gauchazh.clicrbs.com.br/opiniao/noticia/2017/02/oded-grajew-lei-do-plano-de-metas-chega-aporto-alegre-9714721.html>. Acesso em: 09 jan. 2018.

${ }^{6}$ A exposição de motivos integra o processo n.o 0307/12, que identifica o Projeto de Emenda à Lei Orgânica, pelo n.. $002 / 12$, sendo composta de três páginas sem numeração. Disponível em: <http://www.camarapoa.rs.gov.br/draco/processos/114680/003072012PELO_PROJETO_52488108_113 003072012PELO_PROJETO_52488108_113.pdf>. Acesso em: 18 ago. 2018.
} 
aproximação com o programa de metas da cidade de São Paulo, cuja aprovação contou com a atuação da Rede Nossa São Paulo, uma das entidades coordenadoras do Programa Cidades Sustentáveis:

Assim, a exemplo da Capital paulista, [...] entendemos oportuno disponibilizar este importante mecanismo de controle e transparência da gestão Municipal, com adequações à realidade de Porto Alegre, que tem, na democracia participativa, um dos mais importantes pilares de controle social, convergente com a democracia representativa (CMPA, 2012, s. p.).

Com isso fica claro que a emenda aprovada pela Câmara de Vereadores de Porto Alegre tem ligações explícitas com o Programa Cidades Sustentáveis, o que tornou necessário conhecer um pouco mais a respeito das linhas gerais desse programa e, mais especificamente, o que esse apresenta no que se refere à educação.

Conforme documentos que divulgam o PCS, são disponibilizadas ferramentas para os municípios que se engajarem, sendo dado destaque para a plataforma composta por 12 eixos temáticos. Sobre essa plataforma, o Relatório Anual do Programa do ano de 2016 traz o seguinte registro:

\begin{abstract}
A plataforma reúne um conjunto de indicadores associados a esta agenda e um banco de boas práticas, com casos exemplares nacionais e internacionais como referências a serem perseguidas pelos municípios, ressaltando políticas públicas que já apresentam bons resultados em todas as áreas da administração. A proposta é evidenciar que é possível fazer diferente, incentivando as transformações necessárias nas lideranças políticas para um presente melhor sem inviabilizar o futuro das próximas gerações.

Esta Plataforma foi inspirada nos compromissos de Aalborg (Dinamarca) - um pacto político com o desenvolvimento sustentável que já foi assinado por mais de 650 municípios, principalmente europeus. Os compromissos consideram a participação da comunidade local na tomada de decisões (RELATÓRIO ANUAL DO PROGRAMA, 2016, p. 9).
\end{abstract}

Nos documentos do PCS (2012), são apresentados cada um dos 12 eixos com seus objetivos gerais e específicos. Especificamente no que diz respeito à educação, é possível localizar o eixo 7, Educação para a sustentabilidade e qualidade de vida, em que constam os seguintes objetivos:

Geral

7. Integrar na educação formal e não formal valores e habilidades para um modo de vida sustentável e saudável.

Específicos

7.1 Prover a todos, crianças, adolescentes, jovens, adultos e idosos, oportunidades educativas que lhes permitam papel protagonista no desenvolvimento sustentável local e regional; 


\begin{abstract}
7.2 Garantir a implementação do tema da sustentabilidade de forma transversal nos currículos e propostas pedagógicas;

7.3 Incentivar o papel dos meios de comunicação de massa na conscientização sobre os desafios socioambientais e sobre as mudanças culturais necessárias à sustentabilidade;

7.4 Reconhecer a importância da educação ética, baseada em valores, para uma condição de vida sustentável;

7.5 Garantir a universalização e a qualidade do ensino em todos os níveis, assegurando a participação da comunidade na gestão escolar;

7.6 Prover a todos o ensino do esporte educacional, como maneira de se promover a auto-estima, o desenvolvimento pessoal, o trabalho em equipe, o respeito à diversidade e a promoção da saúde (PROGRAMA CIDADES SUSTENTÁVEIS, 2012, p. 9).
\end{abstract}

Outro destaque importante em relação ao Programa Cidades Sustentáveis é que este explicita a ideia de buscar o comprometimento de que cada candidato a cargo no executivo tanto com o desenvolvimento sustentável, como com o compromisso de dar publicidade por meio de relatórios que expressem os avanços, a evolução dos indicadores e as ações desenvolvidas. Ou seja, é preciso que haja uma conexão entre o que o então candidato defendeu como programa de governo e aquilo que ele efetivará na gestão.

No caso da legislação municipal de Porto Alegre, o parágrafo 1o do art. 94 coloca isso de forma explícita, além de estabelecer a vinculação com as deliberações do Orçamento Participativo (OP). É importante destacar que o OP organizado nos anos 1990 se configurou em referência para outras cidades, estados e países, como modelo de participação da população na definição das prioridades de investimentos públicos, embora não tenha se mantido nas últimas administrações com o mesmo funcionamento pelo qual ganhou visibilidade.

Levando em conta a legislação aprovada, as notícias destacadas e as informações a respeito do Programa Cidades Sustentáveis, é possível inferir que a criação do Prometa em Porto Alegre mantém estreitas ligações com o PCS. A seguir será analisado o primeiro Programa de Metas de Porto Alegre, 2017-2020, apresentado pelo executivo municipal no final do mês de março de 2017.

\title{
AS METAS E INDICADORES PROPOSTOS PARA 2017-2020
}

Atendendo ao que determina a Lei Orgânica, o atual mandatário encaminhou o primeiro Programa de Metas de Porto Alegre - Prometa 2017-2020 - no final do mês de março e realizou audiência pública para a sua discussão. 0 referido plano foi organizado em três eixos: desenvolvimento social; infraestrutura, economia, serviços e 
sustentabilidade; gestão e finanças, que se desdobram em 16 objetivos estratégicos e 58 metas.

No que diz respeito à educação, está inserida no eixo do desenvolvimento social e constam dois objetivos estratégicos: aumentar e qualificar a oferta de vagas da educação infantil, desdobrado nas metas 19 e 20; melhorar a qualidade do ensino fundamental, composto pelas metas 21 a 27.

As metas relacionadas à educação infantil, 19 e 20, tratam respectivamente a respeito da ampliação da oferta de vagas para crianças de 0-3 anos e a da universalização do atendimento na faixa etária de 4-5 anos. Quanto ao ensino fundamental, temos o seguinte: as metas 21 e 22 tratam do Ideb; as metas 23-26 definem percentuais para a qualificação do nível de proficiência nas áreas de linguagem e matemática tanto nos anos iniciais como nos anos finais; e a meta 27 propõe que semestralmente $100 \%$ dos alunos da Rede Municipal de Ensino - RME - tenham garantido o acompanhamento do aprendizado.

Considerando que no parágrafo $1^{\text {o }}$ do artigo 94 da Lei Orgânica Municipal foi definido que o Prometa "[...] deverá observar as diretrizes apresentadas na campanha eleitoral, os programas e as ações de governo em andamento, as leis orçamentárias e as deliberações oriundas das assembleias do Orçamento Participativo", o próximo passo foi comparar o conteúdo do plano apresentado no Prometa com o programa registrado pelo então candidato a prefeito.

Para a educação da cidade de Porto Alegre foram apresentados seis tópicos no programa de governo do então candidato, quais sejam:

PRIMEIRA INFÂNCIA: Ampliar e qualificar programas para a primeira infância visando a promoção do desenvolvimento integral do ser humano, incrementando vínculos afetivos e fortalecendo a identidade familiar, desde a gestação até os seis anos de idade.

EDUCAÇÃO INFANTIL: Garantir acesso da população às creches, descentralizando-as e tornando-as mais próximas das residências das famílias e locais com grande fluxo de trabalhadores. Qualificar o atendimento na Educação Infantil, mediante a formação continuada dos profissionais. Ampliar a oferta de pré-escola na faixa etária de 4 a 5 anos.

ENSINO FUNDAMENTAL: Realizar ações que oportunizem a cada aluno se recuperar na progressão de séries, garantindo que o estudante esteja localizado no ano adequado à sua idade, melhorando os resultados de rendimento e os índices de aprovação da rede.

QUALIDADE EM TODOS OS NÍVEIS: Propor uma parceria com os professores em nome dos alunos da rede municipal de POA, a fim de melhorar os indicadores, alcançando os índices do IDEB propostos nos Planos de Educação.

EDUCAÇÃO EM TEMPO INTEGRAL E CONTRA-TURNO [sic] ESCOLAR: Intensificar esforços para oferecer educação em Tempo Integral na rede pública 
de ensino. Realizar atividades utilização do contra-turno [sic] escolar, utilizando a estrutura disponível das escolas, e em parceria com instituições ligadas ao serviço social, arte, cultura e esportes do município.

INFRA-ESTRUTURA [sic]: Executar programa permanente de manutenção da infra estrutura $[s i c]$ de ensino no município, conservando prédios, áreas de esporte e renovação dos materiais utilizados para o ensino (PROGRAMA DE GOVERNO, 2016, p. 10, grifos no original).

Considerando que o Programa de Metas deva contemplar as proposições e diretrizes apresentadas no programa de governo, é possível constatar que em relação à educação infantil as metas propostas contemplam o programa de governo apresentado. No que diz respeito à educação em tempo integral e à infraestrutura, estas não estão contempladas no Prometa. Quanto ao ensino fundamental e à qualidade em todos os níveis, é possível afirmar que são os dois temas que dominam as metas apresentadas para a educação municipal para o período de 2017-2020. No caso do ensino fundamental, predominou a questão do rendimento e dos resultados, ambos relacionados à questão dos resultados da Prova Brasil, que, por sua vez, repercutem tanto nos índices de proficiência como nos resultados do Índice de Desenvolvimento da Educação Básica - Ideb.

Mas é importante enfatizar que os dados do Ideb são uma composição entre as médias obtidas nas avaliações realizadas pelo Instituto Nacional de Estudos e Pesquisas Educacionais Anísio Teixeira - Inep - e os índices de aprovação obtidos a partir do Censo Escolar, informados pelas escolas ao mesmo órgão.

Outro destaque importante a ser feito é quanto à constatação da ausência de metas relacionadas a outras modalidades e etapas da educação básica ofertadas nas escolas da rede municipal de ensino, mais especificamente a educação especial, a educação de jovens e adultos e também o ensino médio. Considerando que o Prometa envolve os quatro anos da gestão, é preocupante que essas modalidades estejam ausentes do planejamento apresentado pela administração municipal, principalmente porque a RME concentra elevado número de alunos atendidos tanto na educação especial como na educação de jovens e adultos, inclusive sendo responsável pela maioria do atendimento ofertado no território de Porto Alegre nessas modalidades.

Também chama a atenção a proposta de parceria como os professores, presente no tema da qualidade em todos os níveis. Esse destaque é feito, pois durante o recesso escolar foram determinadas modificações na organização dos tempos das escolas sem nenhum tipo de diálogo justamente com os professores, sendo que o assunto veio a público durante o período de recesso escolar, no início de 2017, quando o comunicado foi 
feito para os diretores. Cabe observar que as modificações introduzidas incluíram a retirada do horário de reunião pedagógica ${ }^{7}$ da grade de horário das escolas, sem que a essa fosse remanejada para outro momento, o que inviabilizou o processo de planejamento pedagógico coletivo e motivou mobilização intensa por parte dos professores, sem que houvesse recuo por parte da gestão da Secretaria de Educação.

\section{COLOCANDO EM DISCUSSÃO}

É possível pensar a inserção do novo inciso na Lei orgânica de Porto Alegre considerando o contexto em que se deu a influência do Programa Cidades Sustentáveis. Analisando quem integra o PCS, é possível localizar atores que estão sintonizados e atentos às políticas públicas e aos processos de participação em curso na cidade desde os anos de 1990, e que parecem estreitamente relacionados com a proposição do programa de metas, principalmente se considerarmos o que prevê quanto ao envolvimento da população no acompanhamento, monitoramento e avaliação do referido planejamento. Mesmo que tenha ocorrido uma mudança no grupo político que esteve à frente da gestão municipal no período de 1989-2004, ações de planejamento ligadas ao Orçamento Participativo foram mantidas por quem esteve à frente da gestão pública no período subsequente de 2005-2016. Assim, é possível afirmar que, quando da aprovação do Prometa, o contexto da produção do texto estava favorável, sem evidenciar naquele momento sinais de ruptura quanto à participação da população na definição das prioridades de investimentos e orientação das políticas públicas.

Mas cabe lembrar o que Mainardes (2006) recomenda: “A política não é feita e finalizada no momento legislativo e os textos precisam ser lidos com relação ao tempo e ao local específico de sua produção" (MAINARDES, 2006, p. 52). Se durante o debate para aprovação da alteração não houve grandes controvérsias e enfrentamentos no debate de ideias, convém lembrar que o tempo em que foi produzida essa alteração na Lei Orgânica precedia o período eleitoral. Assim, o chamado contexto da prática, o momento em que a legislação passaria a viger, foi cercado de incertezas, visto que além de haver a troca do gestor, houve o rompimento de um ciclo de 12 anos de uma coligação, ocasião vista por

\footnotetext{
${ }^{7}$ A reunião pedagógica estava inserida na organização de todas as escolas desde os anos 1990, sendo que no dia de sua realização o horário de atendimento dos alunos era diferenciado. Antes da determinação da Secretaria de Educação a carga horária semanal dos alunos da Rede Municipal de Ensino de Porto Alegre era de 20 horas e 30 minutos. Com a modificação a carga horária passou a ser de 20 horas. Na prática, além da perda do horário de reunião pedagógica, houve uma redução na carga horária semanal de atendimento dos alunos.
} 
muitos defensores de políticas de gestão associadas a modelos neoliberais, como é o caso do grupo político que assumiu a gestão municipal e de parte dos vereadores que integram o grupo de apoio a essa, como extremamente propícios para a implementação de mudanças ou mesmo rupturas. É pertinente destacar novamente Mainardes: “[...] o ponto-chave é que as políticas não são simplesmente 'implementadas' dentro desta arena (contexto da prática), mas estão sujeitas à interpretação e, então, a serem 'recriadas'” (MAINARDES, 2006, p. 53). Tal colocação permite pensar sobre a possibilidade de que o Programa apresentado pelo atual gestor municipal, por ser o primeiro a ter essa responsabilidade, esteja mais propenso a múltiplas adequações e modificações de modo a atender às concepções de quem está assumindo a gestão e não tanto o espírito da lei quando da sua aprovação.

O Prometa 2017-2020 inicia com uma apresentação assinada pelo prefeito e pelo vice-prefeito, na qual está registrado o seguinte:

\begin{abstract}
Ainda no período de campanha, afirmamos que um novo tempo exige uma nova atitude para administrar Porto Alegre. Um tempo com absoluta transparência na aplicação de recursos públicos e, principalmente, de compromissos honrados. Assim podemos trabalhar na construção de uma cidade melhor de verdade para o Seu João e a Dona Maria (PROMETA, 2017, s. p).
\end{abstract}

Entretanto, em evento realizado no mês de novembro de 2017, o atual prefeito fez uma declaração polêmica contradizendo esse registro, fato amplamente noticiado em jornais e páginas eletrônicas ${ }^{8}$. Ao abordar em seu discurso a respeito das reformas necessárias na gestão municipal, o prefeito manifestou ser uma irresponsabilidade delegar ao "Seu João e à Dona Maria" tal tarefa e apontou que caberia ao que ele definiu como "elites" da comunicação, empresarial e política, tal responsabilidade.

Se estabelecermos algumas conexões entre essa manifestação e o modo como foram determinadas as mudanças na organização dos tempos das escolas municipais, é possível localizar em uma publicação sob a responsabilidade do Banco Mundial um modo de implementar políticas que segue um receituário dessa organização:

Os líderes políticos podem criar alianças pró-reformas eficazes com líderes empresariais e sociedade civil por meio de campanhas de comunicações que expõe claramente as falhas atuais do sistema educacional [...]. A oportunidade para a reforma é maior se lançada no início de uma administração. Na maioria

\footnotetext{
${ }^{8} \mathrm{O}$ assunto foi registrado inclusive na página da Prefeitura Municipal de Porto Alegre. Disponível em: http://www2.portoalegre.rs.gov.br/portal_pmpa_novo/default.php?p_noticia=999193875\&MARCHEZAN +DESTACA+A+IMPORTANCIA+DAS+REFORMAS+EM+EVENTO+DA+AGAS. Acesso em: 14 jan. 2018.
} 
dos casos, o processo é contencioso e os sindicatos têm um forte interesse em posterga-lo. Se agirem rapidamente, líderes beneficiam-se do seu ponto de influência política máxima e estabelecem a educação como prioridade máxima. (BRUNS, LUQUE, 2014, p. 49).

Assim, no momento da implementação, que se insere no contexto da prática, temos todo um tensionamento que é resultado do modo como a atual gestão vem conduzindo a dinâmica que envolve as políticas públicas.

Ao adotar como metas para o ensino fundamental apenas as que contemplam aspectos relacionados a resultados balizados pelas notas obtidas em avaliações de larga escala, o gestor atual adota uma concepção de avaliação, sem que essa passe por um debate com a comunidade escolar, tal como está definido na legislação que criou o Sistema Municipal de Ensino.

Aqui novamente as palavras de Mainardes (2006) podem contribuir para compreender o processo em curso na implementação do Prometa em Porto Alegre:

[...] o contexto da prática exige a análise de como a política é reinterpretada pelos profissionais que atuam no nível micro e ainda a análise das relações de poder, resistências etc. Tanto no contexto macro quanto no micro, as relações de poder são particularmente significativas para se entender a política ou o programa. A atividade micropolítica pode ser identificada por meio da observação de conflitos, do estilo das negociações durante o processo decisório, das restrições colocadas sobre as questões a serem discutidas e decididas, bem como por meio da identificação de estratégias, influências e interesses empregados nos diferentes contextos e momentos do ciclo de políticas (MAINARDES, 2006, p. 60).

É de domínio público que ao longo deste primeiro ano e meio de gestão o atual mandatário não primou por manter relações amistosas com os profissionais que atuam nas escolas municipais, os quais têm grande responsabilidade na consecução das metas estabelecidas no Prometa, visto que, independentemente da vontade do prefeito, há um trabalho pedagógico a ser desenvolvido.

As metas propostas para os quatro anos de gestão não indicam as estratégias que serão utilizadas para que se efetivem. As quatro metas do ensino fundamental, ligadas à proficiência em português e matemática para anos iniciais e finais, apresentam problemas na fórmula de cálculo do indicador técnico, pois ao invés de fazer referência a número de pontos, considera número de questões, o que é um erro grosseiro e denota pouca familiaridade com a forma como o Inep trata desse tema.

Se compararmos o que consta no programa apresentado quando da candidatura ao cargo de prefeito e o Prometa, é possível verificar que a ausência de metas relacionadas 
ao ensino em tempo integral e à infraestrutura coloca-as na condição de promessas de campanha.

O programa do então candidato traz a seguinte afirmação:

\begin{abstract}
Investir na qualidade da educação ofertada à criança e ao adolescente na rede municipal de ensino significa projetar um futuro melhor para o desenvolvimento econômico e social de nossa cidade. A educação é fator de independência do ser humano, indispensável para a transformação do indivíduo em um ser humano produtivo e socialmente integrado (PROGRAMA, 2016, p. 10).
\end{abstract}

Mas se dentro das proposições do referido programa e das metas apresentadas para a gestão do período de 2017-2020 não há nenhuma referência a questões pedagógicas e a ênfase das metas propostas está no resultado do Ideb, no resultado da Prova Brasil e na realização sistemática de avaliações semestrais, será que o propósito da criação do Programa de Metas será contemplado?

Ao comparar o Prometa apresentado pelo atual prefeito com os objetivos específicos que constam no Programa Cidades Sustentáveis, resta dúvidas se a atual administração pretende de alguma forma manter vinculação com este programa, embora os indícios de que, quando da proposição e aprovação da criação do Prometa, houvesse conexão entre ambos.

\title{
CONSIDERAÇÕES FINAIS
}

Após analisar o texto da lei, as notícias relacionadas a sua promulgação e o processo de implementação do Prometa, fica evidente que se faz necessário desenvolver um processo de avaliação quanto à sua aplicação. Embora essa etapa não esteja referida no corpo da lei, penso ser pertinente que o legislativo municipal tome a iniciativa de viabilizar tal ação, visto que o projeto aprovado foi por iniciativa do legislativo.

Neste momento a fase em que o Prometa se encontra é a de implementação. Com isso, é pertinente destacar as palavras de Arretche: “A implementação [...] corresponde a uma outra fase da 'vida' de um programa, na qual são desenvolvidas as atividades pelas quais se pretende que os objetivos, tidos como desejáveis, sejam alcançados" (ARRETCHE, (2001, p. 47).

Considerando que a implementação de políticas produz efeitos, é importante que haja tanto o monitoramento como a avaliação desses. Draibe (2001) lembra que: 
As políticas ou programas têm vida. Nascem, crescem, transformam-se, reformam-se. Eventualmente estagnam, às vezes morrem. Percorrem, então, um ciclo vital, um processo de desenvolvimento, de maturação e, alguns deles, de envelhecimento ou decrepitude. É este ciclo (ou alguns de seus momentos) que constitui o objeto das avaliações de processos (DRAIBE, 2001, p. 26).

A lei que criou o Prometa tem caráter permanente, mas por envolver um programa que dê conta das metas por um prazo de quatro anos envolve um processo diferenciado em relação às demais políticas.

Quanto ao conteúdo aprovado na emenda, já há sinais de que haverá problemas para a sua consecução, visto que até o final do primeiro semestre de 2018 o executivo municipal não atendeu ao disposto no $5^{\circ}$ do art. 94, que determina a divulgação dos indicativos de desempenho do Prometa pelo menos uma vez por ano.

Nesse sentido preocupa que a Câmara de Vereadores, de onde partiu a iniciativa para a alteração da Lei Orgânica Municipal, não tenha agido para o cumprimento dessa determinação e a própria aplicabilidade da lei, visto que não há notícias e ações no sentido de problematizar o conteúdo que integra o Prometa 2017-2020 e a articulação com o programa registrado pelo gestor eleito.

Outro elemento para reflexão diz respeito à proposição de emenda à lei orgânica, encaminhada pelo atual gestor, em tramitação desde maio de 2017, a qual, dentre outras proposições, amplia o prazo para que o Prometa seja encaminhado para análise na Câmara de Vereadores, passando de 90 dias para 120 dias.

Para questões futuras talvez fosse pertinente analisar o Programa de Metas à luz da legislação que orienta a transparência e o acesso a informações, visto que o Prometa deve observar as leis orçamentárias, assim como em relação à influência e à conexão com o Programa Cidades Sustentáveis, visto que, neste momento, as metas apresentadas para a educação no Prometa estão um tanto quanto distantes do que é proposto no referido programa.

\section{REFERENCIAS}

ARRETCHE, Marta Tereza da Silva. Uma contribuição para fazermos avaliações menos ingênuas. In: BARREIRA, Maria Cecília e CARVALHO, Maria do Carmo. Tendências e perspectivas na avaliação de políticas e programas sociais. São Paulo, IEE/PUC SP, 2001.

BRUNS, Barbara; LUQUE, Javier. Professores Excelentes Como melhorar a aprendizagem dos estudantes na América Latina e no Caribe. Washington, D.C.: Banco Mundial, 2014. 
CÂMARA MUNICIPAL DE VEREADORES DE PORTO ALEGRE - CMPA. Projeto de Emenda à Lei Orgânica - PELO no 002/12. Disponível em: < http://www.camarapoa.rs.gov.br/draco/processos/114680/003072012PELO_PROJET O_52488108_113003072012PELO_PROJETO_52488108_113.pdf> Acesso em: 18 ago.2018.

DRAIBE, Sônia Miriam. Avaliação de implementação: esboço de uma metodologia de trabalho em políticas públicas. In: BARREIRA, Maria Cecília e CARVALHO, Maria do Carmo. Tendências e perspectivas na avaliação de políticas e programas sociais. São Paulo, IEE/PUC SP, 2001.

GRAJEW, Oded. Lei do Plano de Metas chega a Porto Alegre. Jornal Zero Hora. Porto Alegre, 07.fev.2017. Disponível em:

https://gauchazh.clicrbs.com.br/opiniao/noticia/2017/02/oded-grajew-lei-do-planode-metas-chega-a-porto-alegre-9714721.html > Acesso em: 09 jan.2018

MAINARDES, Jefferson. Abordagem do ciclo de políticas: uma contribuição para a análise de políticas educacionais. Educação e Sociedade. Campinas, vol. 27, n. 94, p. 47-69, jan./abr. 2006.

PORTO ALEGRE. Emenda à Lei Orgânica no 36, de 12 de agosto de 2015. Inclui inc. XXII no caput e $\S \S 1^{\circ}$ a $6^{\circ}$ no art. 94 e $\S 6^{\circ}$ no art. 116 da Lei Orgânica do município de Porto Alegre, incluindo o programa de metas (Prometa) no rol de competências privativas do prefeito e determinando que as leis orçamentárias incorporem as prioridades, os indicadores de desempenho e as metas quantitativas e qualitativas desse programa. Disponível em: < https://leismunicipais.com.br/a/rs/p/porto-

alegre/emenda-a-lei-organica/2015/4/36/emenda-a-lei-organica-n-36-2015-inclui-incxxii-no-caput-e-1-a-6-no-art-94-e-6-no-art-116-da-lei-organica-do-municipio-de-portoalegre-incluindo-o-programa-de-metas-prometa-no-rol-de-competencias-privativas-doprefeito-e-determinando-que-as-leis-orcamenta-rias-incorporem-as-prioridades-osindicadores-de-desempenho-e-as-metas-quantitativas-e-qualitativas-desse-programa > Acesso em: 09 jan.2018

. Prometa. Programa de Metas 2017-2020. Disponível em: < http://lproweb.procempa.com.br/pmpa/prefpoa/smpeo/usu_doc/prometa_poa_20172020.pdf > Acesso em: 09 jan.2018

PROGRAMA CIDADES SUSTENTÁVEIS. Rede Nossa São Paulo. Rede Social Brasileira por Cidades Justas e Sustentáveis. Instituto Ethos de Empresas e Responsabilidade Social. Disponível em: < http://www.cidadessustentaveis.org.br/downloads/publicacoes/publicacao-programacidades-sustentaveis.pdf > Acesso em: 13 jan.2018.

. Relatório Anual Programa Cidades Sustentáveis 2015-2016. Disponível em: <http://www.cidadessustentaveis.org.br/arquivos/relatorio_cidades_sustentaveis_201 5-2016.pdf > Acesso em: 13 jan.2018. 
PROGRAMA DE GOVERNO. Candidatura Nelson Marquezan. PSDB/Porto Alegre. Disponível em: < http://estaticog1.globo.com/2016/11/01/proposta_governo1471291722755.pdf > Acesso em: 14 jan.2018. 


\title{
JORNAL DE PoLíticas EDUCACIONAIS POLITICAS EDUCACIONA Volume 13

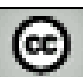

SORERIGHIS RESERNED O Copyright é retido pelo/a autor/a (ou primeiro co-autor) que outorga o direito da primeira publicação ao Jornal de Políticas Educacionais. Mais informação da licença de CreativeCommons encontram-se em http://creativecommons.org/licenses/by-nc-nd/2.5. Qualquer outro uso deve ser aprovado em conjunto pelo/s autor/es e pelo periódico.

JoRnal DE Políticas EduCACiOnais é uma publicação do Núcleo de PolíticasEducacionaisdo Setor de Educação da Universidade Federal do Paraná - NuPE/UFPR, em consórcio com a Linha de Pesquisa em Políticas Educacionais do Programa de Pós-Graduação em Educação - PPGE/UFPR, que aceita colaboração, reservando-se o direito de publicar ou não o material espontaneamente enviado à redação. As colaborações devem ser enviadas ao NuPE/UFPR, conforme orientações contidas nas páginas do periódico na internet: http://revistas.ufpr.br/jpe.

\author{
Indexação: \\ BBE - Biblioteca Brasileira de Educação (MEC/INEP) \\ Clase (Base de Datos Bibliográfica de Revistas de Ciencias Sociales y Humanidades) \\ Diadorim - Diretório de Política de Acesso Aberto das Revistas Científicas Brasileiras (IBICT) \\ Google Scholar \\ Index Copernicus \\ Portal de Periódicos (CAPES) \\ SER - Sistema Eletrônico de Revistas da Universidade Federal do Paraná (SER/UFPR) \\ Sumários de Revistas Brasileiras (FUNPEC-RP) \\ DRII - Directory of Research Journals Indexing
}

(Periódico integralmente disponível apenas em via eletrônica)

Jornal de Políticas Educacionais / Núcleo de Políticas Educacionais da Universidade Federal do Paraná NuPE/UFPR - v.1, n. 1 (1ํㅗ semestre de 2007) - Curitiba: NuPE/UFPR.

Volume 13, número 27 - Agosto de 2019

ISSN 1981-1969

1. Educação - Periódicos. 2. Política Educacional - Periódicos. I. NuPE/UFPR

Comitê Editorial:

Elisângela Scaff (UFPR)

Daniela de Oliveira Pires (UFPR)

Ana Lorena Bruel (UFPR)

Conselho Editorial:

Andréa Barbosa Gouveia (UFPR), Fernanda Saforcada (UBA), Gladys Beatriz Barreyro (USP), Gustavo Enrique Fischman, (Arizona State University), Jefferson Mainardes (UEPG), João Ferreira de Oliveira (UFG), Juca Gil (UFRGS), Luiz Souza Júnior (UFPB), Ney Cristina Monteiro de Oliveira (UFPA), Nicolás Bentancur, 
(Universidad de la República de Uruguay), Robert Verhine (UFBA), Rosana Cruz (UFPI), Rubens Barbosa Camargo (USP), Sebastián Donoso Díaz (Universidad de Talca, Chile), TheresaAdrião (UNICAMP), Vera Peroni (UFRGS).

Créditos e Agradecimentos:

Revisão de Língua Portuguesa, Abstract e Resumen: PROGRAMA DE APOIO ÀS PUBLICAÇõES CIENTÍFICAS PERIÓDICAS DA UFPR

Arte e diagramação: TIAGO TAVARES (tiagotav@gmail.com)

\author{
Jornal de Políticas Educacionais \\ Universidade Federal do Paraná \\ Setor de Educação \\ Núcleo de Políticas Educacionais - NuPE/UFPR \\ Avenida Sete de Setembro, 2645 \\ $2^{\circ}$ andar, Sala 213 \\ 80.230-010 - Curitiba - PR - Brasil \\ Tel.: 41-3535-6264 \\ jpe@ufpr.br \\ http://revistas.ufpr.br/jpe
}

